\title{
Sexual Intercourse among Early Adolescents in Semarang, Central Java, Indonesia: Survey using Respondent-Driven Sampling (RDS)
}

Grhasta Dian Perestroika ( $\nabla$ grhastadian@mail.ugm.ac.id)

Gadjah Mada University Faculty of Medicine, Public Health, and Nursing: Universitas Gadjah Mada

Fakultas Kedokteran Kesehatan Masyarakat dan Keperawatan https://orcid.org/0000-0002-4029-0183

Yayi Suryo Prabandari

Gadjah Mada University Faculty of Medicine: Universitas Gadjah Mada Fakultas Kedokteran Kesehatan Masyarakat dan Keperawatan

\section{Siswanto Agus Wilopo}

Gadjah Mada University Faculty of Medicine: Universitas Gadjah Mada Fakultas Kedokteran Kesehatan Masyarakat dan Keperawatan

\section{Research Article}

Keywords: Early Adolescents, Sexual Intercourse, Epidemiology, Prevalence, Indonesia

Posted Date: February 17th, 2021

DOI: https://doi.org/10.21203/rs.3.rs-229588/v1

License: (c) (1) This work is licensed under a Creative Commons Attribution 4.0 International License. Read Full License 


\section{Abstract \\ Background}

Sexual intercourse is a risky behavior among many earlier adolescents (10-14 years), some of whom might ultimately experience unsafe abortion. However, the prevalence of sexual intercourse among earlier adolescents in Indonesia is not known.

\section{Methods}

A cross-sectional behavioral survey was conducted from July to October 2019 among early adolescents who are prone to sexual intercourse (EAWAPTSI) in Semarang, Indonesia. A total of 180 EAWAPTSI aged 10-14 years old ( 115 boys and 65 girls) were recruited using respondent-driven sampling (RDS) in urban areas. A survey with the Open Data Kit (ODK) application was administered to the study participants.

\section{Results}

A total of 180 EAWAPTSI were enrolled, including original seeds. The majority of respondents were male and 14 years old. The RDS-adjusted sexual intercourse prevalence was 38.4\% (95\% Cl: 27.8-49.1). The prevalence was higher among adolescents who were of older age, boys, enrolled in school, and under the care of their mother, had low parental education, discussed sexuality with their parents less frequently and agreed with this behavior at their age.

\section{Conclusions}

The conclusion of this study is that early adolescents have already been exposed to sexual activity. This finding suggests that education on healthy sexual behavior should be started before the age of early adolescence (10-14 years). Education should be comprehensive and address individual risk behaviors, not only to delay sexual debut but also to emphasize the importance of preventing sexually transmitted infections and adolescent pregnancy. In addition, parental involvement is needed. Therefore, it is necessary to increase communication about sexuality between children and parents.

\section{Background}

Sexual behavior in adolescents involves several risks to their life (1). It can lead to unwanted pregnancies, HIV-AIDS and other sexually transmitted diseases $(1,2)$. Although it is considered risky behavior, sexual intercourse still occurs in the lives of many adolescents (3). According to recent research, as many as $11.9 \%$ of teenagers in the world who are less than 15 years old have had sexual intercourse (4). Additionally, adolescents who start engaging in sexual intercourse at the age of 14 years or younger rarely use contraception (3). National studies in Indonesia revealed that the prevalence of sexual 
intercourse among adolescents aged $15-24$ years is $8 \%$ for males and $2 \%$ for females (5). However, the prevalence of sexual intercourse in early adolescents is not known. Data are needed on sexual intercourse prevalence among early adolescents to map the best interventions for these at-risk youths. It is known unsafe and risky sexual behavior can increase teenage pregnancy (6).

Religiously and culturally, sex before marriage is prohibited in Indonesia (7). However, sexual intercourse occurs among unmarried adolescents (5). It is necessary to estimate the prevalence of sexual intercourse among earlier adolescents because there are currently no data on sexual intercourse for this population. A specific method is needed to accurately measure the prevalence of sensitive issues in society (8). The respondent-driven sampling (RDS) method has been applied to measure prevalence in hidden populations $(8,9)$. Some hidden populations that have been successfully captured by the RDS method are drug users, sex workers, people with HIV-AIDS and the prevalence of homosexual behavior (10-20). This method focuses on people with certain characteristics or activities who are connected in social networks and have relationships with other people who have similar characteristics (21). There is a probability calculation in the RDS method that leads to an unbiased estimate of the target population (22). To fill this gap concerning adolescent sexual behaviors, this study was conducted to estimate the prevalence of sexual intercourse among early adolescents who are prone to sexual intercourse (EAWAPTSI) in Semarang, the capital city of Central Java Province, Indonesia. This research is the first study among EAWAPTSI in Indonesia.

\section{Methods}

\section{Study design}

This was a cross-sectional survey among early adolescents using RDS. This method is used in research that involves taboo or stigma in society and surveys at-risk populations that are difficult to reach $(9,23)$. This method was developed to cover the weaknesses of the snowball sampling method by applying calculations of probability and providing material incentives that are given as motivation to the subjects to participate so that respondents are more willing to be fully involved in the study (8). This incentive makes it easier to recruit potential respondents (24). Incentives were given to respondents twice: first, when the respondents were identified as willing to join this research; second, when the respondents provided information about another individual in their network (seed sampling) who had the same characteristics as them, which in this case involved adolescents who had sexual intercourse.

\section{Setting}

Household visits took place in urban Semarang, the capital city of Central Java Province, Indonesia. The study site was selected based on the teenage pregnancy prevalence among 15 to 18 years old in Semarang City as a proxy for the prevalence of sexual intercourse for the younger population.

\section{Participants}




\section{Population and sample recruitment}

They survey was conducted from June to October 2019. Early adolescents were eligible to participate if they 1 ) were early adolescents 10-14 years old, either male or female, who lived in Semarang; 2 ) were believed to have had sexual intercourse, based on the assumption of the recruiter; 3 ) had a valid RDS voucher; 4) agreed to join the survey by providing written informed consent; and 5) had not previously participated in this survey.

Based on the inclusion criteria, we used a key question to recruit participants. The question was, "Are there any of your close friends aged 10 to 14 years old in Semarang who you think have had sexual intercourse?" Since the RDS method is able to reveal hidden populations, we could reach early adolescents by recruitment who were believed by the recruiter to have had sexual intercourse, regardless of whether they had actually participated in this behavior. Therefore, we categorize this population as early adolescents who are prone to sexual intercourse (EAWAPTSI).

Nine EAWAPTSI seeds in Semarang were purposely selected to initiate recruitment chains. The seeds were determined based on discussions with nongovernmental organizations and secondary data from the Semarang City Health Office. The first seed was successfully obtained from the recommendation of a nongovernmental organization, and the other eight were obtained from the development of secondary data from the Semarang City Health Office. The seeds chosen were those who met the study eligibility criteria and who were willing to participate in linking the study to their peers with a similar characteristicin this case, having had sexual intercourse.

The field workers went to the houses of prospective respondents to meet with the prospective respondent and his or her parents or guardians to explain the research process and to obtain approval for data collection. The data collection point was offered to potential respondents, whether at home or elsewhere, depending on the respondent's request. RDS was conducted with the same criteria as the seed subject.

After they gave informed consent and assent, each subject seed was asked to complete the questionnaires provided on a tablet through the Open Data Kit (ODK) and was given the following: 1) a research identity card, 2) incentive for their participation in this research; and 3) up to 6 vouchers to recruit others in their network, with numbers to identify the participants. Each voucher consisted of two parts with different colors. These were recruitment vouchers and vouchers for a gift. Respondents were asked to give the recruitment voucher to friends they knew who had previously had sexual intercourse. Then, the friends were required to contact the researcher and perform the procedure for data collection. Respondents were allowed to exchange the gift voucher for an additional incentive after their friends who received the recruitment vouchers filled in the questionnaires in the ODK. Incentives for participation in the research were as high as IDR 40,000 (approximately 3 USD), and the incentive for success in recruiting new respondents was IDR 25,000 (approximately 2 USD). The maximum number of vouchers to be redeemed was 6 , equal to the number of vouchers given to the respondents. The circulation of the vouchers was carefully recorded and documented by the data collection staff. To reach the next network 
of participants, the field workers asked them key questions. The field workers gave as many recruitment vouchers as requested by the participants and waited to be contacted by the next potential participants. If no one contacted the data collection staff within one week, the field workers contacted the participants who had brought the recruitment vouchers.

To avoid repeated enrollment, participants' physical characteristics were identified, participants had to show their identity card (student card or member of family card) to the field workers, and the recruitment vouchers were assigned unique numbers. Furthermore, the unique number on the voucher was used as the respondent's identity number. Confidentiality was ensured by this anonymous identification method that did not use the names of any of the respondents or participants.

\section{Sample size}

The minimum number of respondents to identify the prevalence of sexual intercourse with RDS methods in this research was 108. The minimum sample size in this research was determined by the size sample of the RDS approach with design effect 2 (deff) and the error standard (Se(P)), which was not more than 0.03 (25). Because data on the proportion of sexual intercourse for teenagers aged 10-14 years were not available, to estimate these data, the researcher used the proportion of teenagers in Indonesia aged 1524 years old who had sexual intercourse, with a male proportion of $8.3 \%$ and a female proportion of $0.9 \%$. When estimated without considering gender, the proportion of teenagers in Indonesia who have had sexual intercourse was $5.08 \%$ (27). The following formula was used to calculate the RDS sample size: $n=\operatorname{deff} \cdot \frac{p(1-p)}{\left((\operatorname{se}(p))^{2}\right.}$.

The design effect is needed to estimate the proportion of the sample by the RDS method because the sample size estimates based on the respondents varied too much. If the RDS estimates are too variable, even if they are unbiased, they might not be useful in practice (25).

The requirement for achieving equilibrium between waves was fulfilled when the number of participants reached 180, which was greater than the calculation of the minimum sample size (108). The convergence of the population proportion between waves was less than 0.02 . This means that there was less opportunity to recruit other respondents.

\section{Ethical considerations}

The study received ethical approval from the Medical and Health Research Ethics Committee of the Faculty of Medicine, Public Health and Nursing, Universitas Gadjah Mada with a number KE/FK/ 0445 /EC/2019. Procedures were put in place to protect the participants against risks.

\section{Data collection training}

Field workers participated in a three-day face-to-face training workshop. The following topics were covered: 1) understanding adolescent development, 2) detailed review of the questions to be asked and ethical research issues with adolescents, 3 ) the RDS method of collecting respondents, 4) research 
instruments, 5) the parental and respondent approval process, 6) confidentiality and privacy, 7) the art of interviewing and collecting data.

\section{Data collection procedures}

A structured questionnaire adapted from the Indonesian Global Early Adolescents Study (GEAS) was employed.(26) It covered sociodemographic characteristics as well as information regarding the frequency of discussing sexuality with parents, attitudes towards sexual intercourse and intention to engage in sexual intercourse and sexual intercourse behaviors.

\section{Data Analysis}

All data were analyzed using RDSAT 7.1.46, including seeds(27). Raw data were prepared in Microsoft Excel according to the format for RDS (including the subject ID, network size, subject vouchers, and a maximum of six entries for the voucher numbers given). Excel files in csv format were imported into RDSAT.

The achievement of equilibrium was determined based on the convergence of the population proportion between waves of 0.017 (less than 0.02). The RDSAT predicts prevalence in the population by adjusting it using the network size.

\section{Results}

The results begin with the recruitment of participants, descriptions of demographic characteristics and prediction of the prevalence of sexual intercourse behavior.

\section{Participant recruitment}

Of the 9 seeds, 54 were given recruitment vouchers. Only $31.4 \%$ of the adolescents who received vouchers contacted us to join the survey. They are referred to as participants in wave 1. In wave 1, a total of 54 recruitment vouchers were given, and $67 \%$ were returned as wave 2 . This was done until wave 10 , when it had reached equilibrium (the convergence of the population proportion between waves was less than 0.02). The total number of participants, including seeds, was 180 . The flow chart of the number of participants recruited and visualization of the recruiting network are presented in Fig. 1 and Fig. 2.

\section{Sociodemographic characteristics}

A total of 180 EAWAPTSI participated, including the original seeds. Table 1 shows the RDSAT calculation (RDS-adjusted). The older their age, the more likely early adolescents are to be connected in a network of friendships that leads them to engage in risky sexual behavior. More than half of the participants were 14 years old, whereas only one-fourth were aged 12 and under. Boys were more likely than girls to be connected in networks of friendship that led them to have risky sexual behavior. In terms of education and primary caregivers, the early adolescents were mostly enrolled in school and were under the care of their mother. The number of participants who were not enrolled in school was only $1 / 5$ of those who 
attended school. Adolescents who were under the care of their mother were five times more prevalent than those who were under the care of their fathers and four times more prevalent than those who were under the care of other family members. The educational background of the parents varied: more than half of the participants had parents with a junior high school to senior high school education, approximately one-fourth had parents with an elementary school education or who were uneducated, and only a few of the participants had parents who had a college education. The more often adolescents communicated about sexuality with their parents, the less likely they were to be in the network of participants in this study. Nearly half of the participants never discussed sexuality with their parents, approximately 3 in 10 teenagers rarely discussed it, and only 1 in 10 teenagers often discussed it. More participants agreed with sexual intercourse behavior and intended to perform this behavior at a later time than those who did not, with a difference of approximately $10 \%$. The participants' sociodemographic characteristics are presented in Table 1. 
Table 1

Sample and parent sociodemographic characteristics, sexual communication, attitude and intention towards sexual intercourse

\begin{tabular}{|c|c|c|c|}
\hline Variables & $n(N=180)$ & RDS-unadjusted \% & RDS-adjusted \% (95\% Cl) \\
\hline \multicolumn{4}{|l|}{ Current age (years) } \\
\hline$<=12$ & 21 & 11.7 & $13.4(7.2-18.6)$ \\
\hline 13 & 53 & 29.4 & $30.3(22.4-42.4)$ \\
\hline 14 & 106 & 58.9 & $56.3(44.8-65.2)$ \\
\hline \multicolumn{4}{|l|}{ Gender identity } \\
\hline Male & 115 & 63.9 & $71.7(59.5-83.6)$ \\
\hline Female & 65 & 36.1 & $28.3(16.4-40.5)$ \\
\hline \multicolumn{4}{|l|}{ Education } \\
\hline Not in school & 33 & 18.3 & $15.7(7.3-21.4)$ \\
\hline In school & 147 & 81.7 & $84.3(78.6-92.7)$ \\
\hline \multicolumn{4}{|l|}{ Caregiver } \\
\hline Mother & 134 & 74.4 & $68.3(55.1-77.4)$ \\
\hline Father & 24 & 13.3 & $13.8(6.8-20.8)$ \\
\hline Other adult family members & 22 & 12.2 & $18(10.7-31)$ \\
\hline \multicolumn{4}{|l|}{ Parental education } \\
\hline Never attended school & 27 & 15 & $15.1(7.2-23.2)$ \\
\hline Primary school & 26 & 14.4 & $14.5(9.3-22)$ \\
\hline Junior high school & 51 & 28.3 & $26.7(17.4-32.1)$ \\
\hline High school & 67 & 37.2 & $39.6(32.2-50.8)$ \\
\hline College & 9 & 5 & $4.1(0.8-8)$ \\
\hline \multicolumn{4}{|l|}{ Discuss sexuality with parents } \\
\hline Never & 87 & 48.3 & $49.9(41.1-60.6)$ \\
\hline Rarely & 65 & 36.1 & $34.1(25.5-44.1)$ \\
\hline Often & 28 & 15.6 & $16.1(8.9-21.6)$ \\
\hline \multicolumn{4}{|c|}{ Attitudes towards sexual intercourse } \\
\hline Agree & 110 & 61.1 & $57.6(47.9-64.9)$ \\
\hline
\end{tabular}




\begin{tabular}{|llll|}
\hline Variables & $\mathbf{n}(\mathbf{N}=180)$ & RDS-unadjusted \% & RDS-adjusted \% (95\% Cl) \\
\hline Disagree & 70 & 38.9 & $42.4(35.1-52.1)$ \\
\hline Intention of sexual intercourse & & & \\
\hline Intend & 103 & 57.2 & $54.2(44.6-61.8)$ \\
\hline Did not intend & 77 & 42.8 & $45.8(38.2-55.4)$ \\
\hline $\begin{array}{l}\text { Note: Cl, confidence interval; RDS, respondent-driven sampling. The selection of options in RDSAT are } \\
\text { dual components at an average network size estimation of 12 mean cell size, 2500 number of } \\
\text { bootstrap resamples, 25\% confidence level alpha and algorithm-type enhanced data smoothing. }\end{array}$ \\
\hline
\end{tabular}

\section{Prevalence of sexual intercourse}

The predicted sexual intercourse prevalence among the EAWAPTSI population was determined from the results of RDSAT analysis that was adjusted by network size. EAWAPTSI who had engaged in sexual intercourse were predicted to be $38.4 \%$ ( $\mathrm{Cl} 95 \% ; 27.8-49.1)$. This prediction was $9.9 \%$ lower than the percentage of the sample (unadjusted), as presented in Table 2.

Table 2

Prevalence of sexual intercourse among EAWAPTSI

\begin{tabular}{|llll|}
\hline $\begin{array}{l}\text { Prevalence of sexual intercourse } \\
\text { among EAWAPTSI }\end{array}$ & $\begin{array}{l}\mathbf{n} \\
\mathbf{N} \\
\mathbf{( 1 8 0 )}\end{array}$ & $\begin{array}{l}\text { RDS-unadjusted \% } \\
\text { sexual intercourse }\end{array}$ & $\begin{array}{l}\text { RDS-adjusted \% sexual } \\
\text { intercourse (95\% Cl) }\end{array}$ \\
\hline Had sexual intercourse & 87 & 48.3 & $38.4(27.8-49.1)$ \\
\hline Never had sexual intercourse & 93 & 51.7 & $61.16(50.9-72.2)$ \\
\hline $\begin{array}{l}\text { Note: Cl, confidence interval; RDS, respondent-driven sampling. The selection of options in RDSAT are } \\
\text { dual components at an average network size estimation of 12 mean cell size, 2500 number of } \\
\text { bootstrap resamples, 25\% confidence level alpha and enhanced algorithm-type data smoothing. }\end{array}$ \\
\hline
\end{tabular}

The prevalence prediction of sexual intercourse based on sociodemographics, sexual communication, attitude and intention towards sexual intercourse is presented in Table 3. The older adolescents' age, the more likely they are to engage in sexual intercourse. The proportion of early adolescents who had engaged in sexual intercourse who were 12 years old and under was only $1 / 11$ of those aged 14 years, while the proportion of those aged 13 years old was half of those aged 14 years old. Boys had slightly higher opportunities to engage in sexual intercourse than girls, with a difference of $8.8 \%$. A higher percentage were registered at school than those who were not attending school, with a difference of $17 \%$. Most of them were cared for by their mother; adolescents in this group were four times more likely to be under the care of their mother than under the care of their father and three times more likely to be under the care of their mother than under the care of other family members. The higher their parents' education level, the less likely early adolescents were to engage in sexual intercourse. Only a few early adolescents who had engaged in sexual intercourse had parents who were college educated. Most of them had 
uneducated or senior high school-educated parents ( $12.6 \%$ and $11 \%$, respectively). The less often early adolescents discussed sexuality with their parents, the greater the adolescents' likelihood of having sexual intercourse was. The number of adolescents who had never discussed sexuality with their parents was four times more than the number of those who discussed it often, and only half the number of teenagers discussed sexuality frequently compared to those who rarely discussed it. Sexual intercourse mostly occurred in adolescents who agreed with this behavior at their age. Only one of 4 EAWAPTSI who engaged in sexual intercourse did not agree with this behavior. Eight out of 10 early adolescents who had engaged in sexual intercourse intended to engage in this behavior at a later time. 
Table 3

Prevalence of sexual intercourse based on sociodemographics, sexual communication, attitude and intention towards sexual intercourse

\begin{tabular}{|c|c|c|c|}
\hline $\begin{array}{l}\text { Prevalence of sexual } \\
\text { intercourse by group }\end{array}$ & $\begin{array}{l}n \\
(\mathrm{~N}= \\
87)\end{array}$ & $\begin{array}{l}\text { RDS-unadjusted \% sexual } \\
\text { intercourse } \\
\text { (Total } \%=48.3 \% \text { ) }\end{array}$ & $\begin{array}{l}\text { RDS-adjusted \% sexual } \\
\text { intercourse }(95 \% \mathrm{Cl})\end{array}$ \\
\hline \multicolumn{4}{|l|}{ Current age (years) } \\
\hline$<=12$ & 3 & 1.7 & $2.1(0-5.9)$ \\
\hline 13 & 23 & 12.8 & $10.4(5.4-21.3)$ \\
\hline 14 & 61 & 33.9 & $23.2(13.9-30.1)$ \\
\hline \multicolumn{4}{|l|}{ Gender identity } \\
\hline Male & 58 & 32.2 & $23(12-34.2)$ \\
\hline Female & 29 & 16.1 & $14.2(8.6-22.4)$ \\
\hline \multicolumn{4}{|l|}{ Education } \\
\hline Not in school & 26 & 11.4 & $11.4(5-15.3)$ \\
\hline In school & 61 & 33.9 & $28.4(19.1-38.6)$ \\
\hline \multicolumn{4}{|l|}{ Caregiver } \\
\hline Mother & 61 & 33.9 & $22.1(13.7-31.6)$ \\
\hline Father & 13 & 7.2 & $5.3(1.6-10)$ \\
\hline Other adult family members & 13 & 7.2 & $7.8(3.7-13.1)$ \\
\hline \multicolumn{4}{|l|}{ Parental education } \\
\hline Never attended school & 19 & 10.6 & $12.6(4.4-17.5)$ \\
\hline Primary school & 15 & 8.3 & $6.8(2.8-11.5)$ \\
\hline Junior high school & 24 & 13.3 & $7.8(2.9-10.5)$ \\
\hline High school & 27 & 15 & $11(4.7-17.6)$ \\
\hline College & 2 & 1.1 & $0.9(0-2.8)$ \\
\hline \multicolumn{4}{|l|}{$\begin{array}{l}\text { Discuss sexuality with } \\
\text { parents }\end{array}$} \\
\hline Never & 47 & 26.1 & $19.3(12.7-26.9)$ \\
\hline Rarely & 30 & 16.7 & $11.9(6.9-20.3)$ \\
\hline Often & 10 & 5.6 & $5.6(1.6-8.9)$ \\
\hline
\end{tabular}




\begin{tabular}{|llll|}
\hline $\begin{array}{l}\text { Prevalence of sexual } \\
\text { intercourse by group }\end{array}$ & $\begin{array}{l}\mathbf{n} \\
\mathbf{( N =}\end{array}$ & $\begin{array}{l}\text { RDS-unadjusted \% sexual } \\
\text { intercourse } \\
\text { (Total \% = 48.3\%) }\end{array}$ & $\begin{array}{l}\text { RDS-adjusted \% sexual } \\
\text { intercourse (95\% Cl) }\end{array}$ \\
\hline $\begin{array}{l}\text { Attitudes towards sexual } \\
\text { intercourse }\end{array}$ & & & $28(21.6-39.4)$ \\
\hline Agree & 66 & 36.7 & $8.6(3-12.5)$ \\
\hline $\begin{array}{l}\text { Disagree } \\
\text { Intention of sexual } \\
\text { intercourse }\end{array}$ & 11.7 & \\
\hline $\begin{array}{l}\text { Intend } \\
\text { Did not intend }\end{array}$ & 66 & 36.7 & $32.9(23.4-42.8)$ \\
\hline $\begin{array}{l}\text { Note: Cl, confidence interval; RDS, respondent-driven sampling. The selection of options in RDSAT are } \\
\text { dual components at an average network size estimation of 12 mean cell size, 2500 number of } \\
\text { bootstrap resamples, 25\% confidence level alpha and enhanced algorithm-type data smoothing. }\end{array}$ \\
\hline
\end{tabular}

\section{Discussion}

This study estimated the prevalence of sexual intercourse among EAWAPTSI using the RDS method. We found that the prevalence of sexual intercourse was higher among those with the following characteristics: older age, male, enrolled in school, under the care of their mother, low parental education, less discussion of sexuality with their parents, and agreed with this behavior at their age. Most of them also intended to perform this behavior again in the future. The importance of this finding is that we identify the prevalence of sexual intercourse among early adolescents, which can be used as a basis for consideration for interventions. The RDS method should be used rather than regular surveys to reach adolescents who have already had sexual intercourse because adolescents can more easily invite members of their networks who have had sexual intercourse to join the study.

Our study differs from previous research in terms of the age of participants and the methods used to reveal adolescent sexual behavior. Compared to other research in Indonesia, the prevalence of sexual intercourse among EAWAPTSI in Semarang was relatively higher than among the general adolescent population, even compared to adolescents who are over 15 years old $(5,28)$. There are no national data on the prevalence of sexual intercourse among adolescents aged 10-14 years. The higher prevalence of sexual intercourse in this study can be explained by the fact that the RDS method is used specifically for capturing events in hidden populations $(8,9)$, whereas previous studies used a household national survey (5) and school-based approach (28), which can be influenced by family and peer pressure to maintain secrecy.

Some of our research results are similar to previous studies that show that the prevalence of sexual intercourse is higher in the following conditions: older age group $(29)$, male $(26,29)$, low parental 
education (30), poor communication between parents and children about sexuality (31-33), and adolescents' agreement with sexual intercourse behavior $(34,35)$. However, there are differences from other studies that state that adolescents whose sexual debut is at the age of less than 15 years are less likely to complete school (36). In this study, the high prevalence of sexual intercourse among adolescents who were registered in school was because most of the adolescent population in Indonesia is enrolled in school due to government regulations that eliminate school fees and obligate children to attend school to the junior high school level (37).

Sexual intercourse behavior that occurs in early adolescence can be correlated with the development of sexual maturity and its effect on sexual behavior (29). Sexual maturity in female adolescents begins at an earlier age that is marked by the onset of menarche (38). The higher prevalence of sexual intercourse in boys may be related to differences in the developmental stages of boys and girls, because during this time, boys may think more about pleasure than the risks that may occur (26). In addition, parental education has a positive correlation with knowledge and methods of conveying sex education to children so they can make safe and appropriate sexual decisions (30). Most of the early adolescents who had engaged in sexual intercourse were under the care of their mothers. Poor communication about sexuality also has an impact on risky behavior (31-33) because when teenagers and their parents do not feel comfortable discussing sexuality, this may lead to a lack of advice for adolescents (39). Adolescents' agreement with sex before marriage tends to lead to their intention and behavior to have sex before marriage $(34,35)$.

A limitation of this study was the possibility of bias in the recruitment of participants. It was possible for participants to ask for the maximum number of recruitment vouchers and take the survey more than once to obtain the greatest incentive possible. However, to minimize this bias, we limited the number of recruitment vouchers to a maximum of 6 . In addition, to avoid repeated enrollment, the participants' physical characteristics were recognized, participants had to show their identity card (student card or family card) to the field workers, and recruitment vouchers were assigned a unique number. However, we succeeded in determining the prevalence of sexual intercourse in early adolescents using the RDS method. This finding had not been previously reported in Indonesia. The prevalence of sexual intercourse among early adolescents was revealed by the RDS method based on the premise that peers are better able than outreach workers and researchers to locate and recruit other members of a hidden population (40),(41).

The findings indicate that adolescents aged 10-14 years have been exposed to sexual activity, so it is necessary to provide education on healthy sexual behavior. Education should focused on educating adolescents about safer sexual behaviors and increasing adolescents' resilience (42-44).

\section{Conclusions}

The conclusion of this study is that early adolescents have already been exposed to sexual activity. Higher prevalence is related to older age, male gender, enrollment in school, maternal care, low parental 
education, less discussion of sexuality with parents and agreement with this behavior at their age. The findings of this study suggest that education on healthy sexual behavior should be started early, before the age of early adolescence (10-14 years). It must be comprehensive and address individual risk behaviors, not only to delay sexual debut but also to emphasize the importance of the prevention of sexually transmitted infections and adolescent pregnancy. There are two ways to prevent sexual intercourse behavior and the risks caused by it. First, school-based interventions are an effective way to reach youth who are enrolled in school. It is necessary to include the topic of healthy sexual behavior, including the prevention of sexually transmitted diseases and the prevention of pregnancy, in both the elementary and junior high school curricula. Teachers need to be given training to present this topic to their students. Second, parents should communicate with out-of-school early adolescents. There needs to be an increase in communication about sexuality between children and their parents. This can be carried out by optimizing the existing government program that was designed to improve adolescents' reproductive well-being, namely, Bina Karya Remaja (Local Program from National Population and Family Planning Board). Through this program, parents should be given training to improve the quality of communication with their children, especially in terms of sexuality.

\section{Abbreviations}

EAWAPTSI: Early adolescents who are prone to sexual intercourse, Cl: Confidence interval, RDS;

Respondent-driven sampling

\section{Declarations}

\section{Ethics approval and consent to participate}

All participants provided written informed consent. Ethical clearance was approved by the medical and health research ethics committee, Faculty of Medicine, Public Health and Nursing, Universitas Gadjah Mada with number KE/FK/ 0445 /EC/2019.

\section{Consent for publication}

Not applicable.

\section{Availability of data and materials}

The datasets used during the current study are available from the corresponding author on reasonable request.

\section{Competing interests}


The authors declare that they have no competing interests.

\section{Funding}

This research was funded by a doctoral research scholarship from Lembaga Pengelola Dana Pendidikan $(L P D P)$, Indonesian Ministry of Finance.

\section{Authors' contributions}

GDP (study implementation, data cleaning, data analysis and manuscript writing), YSP and SAW (study design, manuscript review). All authors read and approved the final manuscript.

\section{Acknowledgments}

The authors would like to acknowledge all of the EAWAPTSI in Semarang for their participation in this study, the facilitators and the data collectors, the Doctoral Program Medicine and Health Science Universitas Gadjah Mada, and the Center for Reproductive Health Studies Universitas Gadjah Mada. The author would also like to thank Abdul Wahab, Althaf Setyawan, Amirah Elyza Wahdi, Nurhoolis Majid and Anggriyani Wahyu Pinandari for their roles.

\section{Authors' affiliations}

1. Student of Doctoral Program Medicine and Health Science, Faculty of Medicine, Nursing \& Public Health, Universitas Gadjah Mada Indonesia

2. Professor at Department of Health Behavior, Environment and Social Medicine, Faculty of Medicine, Public Health and Nursing, Universitas Gadjah Mada Indonesia

3. Professor at Center for Reproductive Health, Universitas Gadjah Mada

4. Professor at Department Biostatistics, Epidemiology and Population Health, Faculty of Medicine, Public Health and Nursing, Universitas Gadjah Mada Indonesia

\section{References}

1. Patrice-Coy C, Johnson EJ, Boodram CAS. Sexual behavior of female adolescents on the spread of HIV/AIDS and other STDs in Carriacou. Medicine. 2016;95(36).

2. Eaton DK, Kann L, Kinchen S, Shanklin S, Ross J, Hawkins J, et al. Youth risk behavior surveillance United States, 2009. Morbidity and mortality weekly report Surveillance summaries (Washington, DC: 2002). 2010;59(5):1-142. 
3. Lara LAS, Abdo CHN. Age at Time of Initial Sexual Intercourse and Health of Adolescent Girls. Journal of Pediatric and Adolescent Gynecology. 2016;29(5):417-23.

4. Smith L, Jackson SE, Jacob L, Grabovac I, Yang L, Johnstone J, et al. Leisure-Time Sedentary Behavior, Alcohol Consumption, and Sexual Intercourse Among Adolescents Aged 12-15 Years in 19 Countries From Africa, the Americas, and Asia. The Journal of Sexual Medicine. 2019;16(9):1355-63.

5. BKKBN, BPS, Kemenkes. Survei Demografi dan Kesehatan Indonesia 2017, Buku Remaja. 2018.

6. Zhan W, Smith SR, Warner LC, North F, Wilhelm S, Nowak A. Sexual behavior and pregnancy among adolescents in foster family homes. International Journal of Adolescent Medicine and Health. 2017;31(2).

7. Utomo I, Utomo A. Indicators and Correlates of Adolescents Pregnancy in Indonesia : Results from 2010 Population Census and 2012 Indonesian Demographic and Health Survey Indonesia: UNFPA Indonesia; 2013 [cited 202028 August]. Available from: https://indonesia.unfpa.org/sites/default/files/pubpdf/Indicator_and_Correlates_of_Adolescent_Pregnancy_in_Indonesia.pdf.

8. Heckathorn DD. Respondent-driven sampling: a new approach to the study of hidden populations. Social problems. 1997;44(2):174-99.

9. Salganik MJ, Heckathorn DD. Sampling and estimation in hidden populations using respondentdriven sampling. Sociological methodology. 2004;34(1):193-240.

10. Iguchi MY, Ober AJ, Berry SH, Fain T, Heckathorn DD, Gorbach PM, et al. Simultaneous Recruitment of Drug Users and Men Who Have Sex with Men in the United States and Russia Using RespondentDriven Sampling: Sampling Methods and Implications. Journal of Urban Health. 2009;86(1):s5-s31.

11. Silva-Santisteban A, Raymond HF, Salazar X, Villayzan J, Leon S, McFarland W, et al. Understanding the HIV/AIDS Epidemic in Transgender Women of Lima, Peru: Results from a Sero-Epidemiologic Study Using Respondent Driven Sampling. AIDS Behavior. 2012;16(1):872-81.

12. Heckathorn DD, Semaan S, Broadhead RS, Hughes JJ. Extensions of Respondent Driven Sampling: A New Approach to the Study of Injection Drug Users Aged 18-25. AIDS Behavior. 2002;6(1):55-67.

13. Johnston LG, Khanam R, Reza M, Khan SI, Banu S, Alam MS, et al. The Effectiveness of Respondent Driven Sampling for Recruiting Males Who have Sex with Males in Dhaka, Bangladesh. AIDS Behavior. 2008;12(1):294-304.

14. Johnston LG, Sabin K, Hien MT, Huong PT. Assessment of Respondent Driven Sampling for Recruiting Female Sex Workers in Two Vietnamese Cities: Reaching the Unseen Sex Worker. Journal of Urban Health. 2006;83(7):i16-i28.

15. Gile KJ. Improved Inference for Respondent-Driven Sampling Data With Application to HIV Prevalence Estimation. Journal of the American Statistical Association. 2011;106(493):135-46.

16. Abdul-Quader AS, Heckathorn DD, McKnight C, Bramson H, Nemeth C, Sabin K, et al. Effectiveness of Respondent-Driven Sampling for Recruiting Drug Users in New York City: Findings from a Pilot Study. Journal of Urban Health. 2006;83(3):459-76. 
17. Wang J, Carlson RG, Falck RS, Siegal HA, Rahman A, Li L. Respondent-driven sampling to recruit MDMA users: a methodological assessment. Drug and Alcohol Dependence. 2005;78:147-57.

18. Hathaway AD, Hyshka E, Erickson PG, Asbridge M, Brochu S, Cousineau M, et al. Research Whither RDS? An investigation of Respondent Driven Sampling as a method of recruiting mainstream marijuana users. Harm Reduction Journal. 2010;7(15):1-11.

19. Ouedraogo HG, Ky-Zerbo O, Grosso A, Goodman S, Samadoulougou BC, Tarnagda G, et al. Human immunodeficiency virus (HIV) among men who have sex with men: results of the first integrated biological and behavioral survey in Burkina Faso, West Africa. BMC Public Health. 2019;19(1):5.

20. Mbunda T, Tarimo EAM, Bakari M, Sandström E, Kulane A. Recruitment using respondent driven sampling, risk behaviors assessment and willingness of young female sex workers (18-25 years) in Dar Es Salaam, Tanzania to participate in HIV vaccine trials. BMC Public Health. 2019;19(1):1537.

21. Goel S, Salganik MJ. Respondent-driven sampling as Markov chain Monte Carlo. STATISTICS IN MEDICINE. 2009;28(1):2202-29.

22. Volz E, Heckathorn DD. Probability based estimation theory for respondent driven sampling. Journal of official statistics. 2008;24(1):79.

23. Johnstona LG, Sabin K. Sampling Hard-to-Reach Populations with Respondent Driven Sampling. Methodological Innovations Online. 2010;5(2):38-48.

24. Dhawan A, Mishra AK, Ambekar A, Chatterjee B, Agrawal A, Bhargava R. Estimating the size of substance using street children in Delhi using Respondent-Driven Sampling (RDS). Asian Journal of Psychiatry. 2020;48:101890.

25. Salganik MJ. Variance estimation, design effects, and sample size calculations for respondentdriven sampling. Journal of Urban Health. 2006;83(1):98.

26. Wilopo SA, Choiriyah I, Pinandari AW, Setyawan A, Nugroho A, Perestroika GD, et al. Early Adolescents' Health in Indonesia; Evidence Based From GEAS-Indonesia, Baseline 2019. YogyakartaIndonesia: Center for Reproductive Health, UGM Faculty of Medicine, Public Health and Nursing; 2020. Available from: http://pkr.fk.ugm.ac.id/file/e4a-national-report_final/.

27. Spiller M, Cameron C, Heckathorn D. Respondent-Driven Sampling Analysis Tool (RDSAT) Version 7.1.46. Ithaca, NY: Cornell University. 2012.

28. Anas R, Suryanto S, Triyoga RS. The Surveillance of Pre-Marital Sexual Behavior in Malang, Indonesia. Health Notions. 2018;2(10):1054-6.

29. Susanto T, Rahmawati I, Wuryaningsih EW, Saito R. Prevalence of factors related to active reproductive health behavior: a cross-sectional study Indonesian adolescent. Epidemiology and Health. 2016;38.

30. Suwarni L. Monitoring parental dan perilaku teman sebaya terhadap perilaku seksual remaja SMA di kota Pontianak. Jurnal Promosi Kesehatan Indonesia. 2009;4(2):127-33.

31. Chen PF. HIV/AIDS Prevention among Young People in East and South-East Asia in the Context of Reproductive and Sexual Health. Asia-Pacific Population Journal. 2008;23(1). 
32. Prasitsuebsai W, Sethaputra C, Lumbiganon P, Hansudewechakul R, Chokephaibulkit K, Truong KH, et al. Adherence to antiretroviral therapy, stigma and behavioral risk factors in HIV-infected adolescents in Asia. AIDS care. 2018;30(6):727-33.

33. Schunter BT, Cheng W-S, Kendall M, Marais H. Lessons learned from a review of interventions for adolescent and young key populations in Asia Pacific and opportunities for programming. JAIDS Journal of Acquired Immune Deficiency Syndromes. 2014;66:S186-S92.

34. Nurmala I, Ahiyanasari CE, Wulandari A, Pertiwi ED. Premarital Sex Behavior Among Adolescent: The Influence of Subjective Norms and Perceived Behavioral Control Toward Attitudes of High School Student. Malaysian Journal of Medicine and Health Sciences. 2019;15(3):110-6.

35. Muanda FM, Gahungu NP, Wood F, Bertrand JT. Attitudes toward sexual and reproductive health among adolescents and young people in urban and rural DR Congo. Reproductive health. 2018;15(1):1-14.

36. Wand H, Bryant J, Worth H, Pitts M, Kaldor JM, Delaney-Thiele D, et al. Low education levels are associated with early age of sexual debut, drug use and risky sexual behaviours among young Indigenous Australians. Sexual health. 2018;15(1):68-75.

37. Indonesia PPR. Peraturan pemerintah republik Indonesia. Nomor 47 tahun 2008 tentang wajib belajar [Internet]. 2008.

38. Wahab A, Wilopo SA, Hakimi M, Ismail D. Declining age at menarche in Indonesia: a systematic review and meta-analysis. International Journal of Adolescent Medicine and Health. 2018;1(aheadof-print).

39. Potter J, Soren K, Santelli J. Predictors of parental knowledge of adolescent sexual experience: United States, 2012. Preventive medicine reports. 2017;6:94-6.

40. Abdul-Quader AS, Heckathorn DD, Sabin K, Saidel T. Implementation and analysis of respondent driven sampling: lessons learned from the field. Journal of urban health. 2006;83(1):1-5.

41. Weir SS, Merli MG, Li J, Gandhi AD, Neely WW, Edwards JK, et al. A comparison of respondent-driven and venue-based sampling of female sex workers in Liuzhou, China. Sexually transmitted infections. 2012;88(Suppl 2):i95-i101.

42. Pinandari AW, Wilopo SA, Ismail D. Pendidikan Kesehatan Reproduksi Formal dan Hubungan Seksual Pranikah Remaja Indonesia. Kesmas: National Public Health Journal. 2015;10(1):44-50.

43. Rahyani NKY, Utarini A, Wilopo SA, Hakimi M. Perilaku seks pranikah remaja. Jurnal Kesehatan Masyarakat Nasional, Kesmas. 2012;7(4):180-5.

44. Rahyani Y, Utarini A, Wilopo SA, Hakimi M. Predictors of premarital sexual initiation on adolescents in Bali: a longitudinal study. BMC public health. 2014;14(1):025.

\section{Figures}




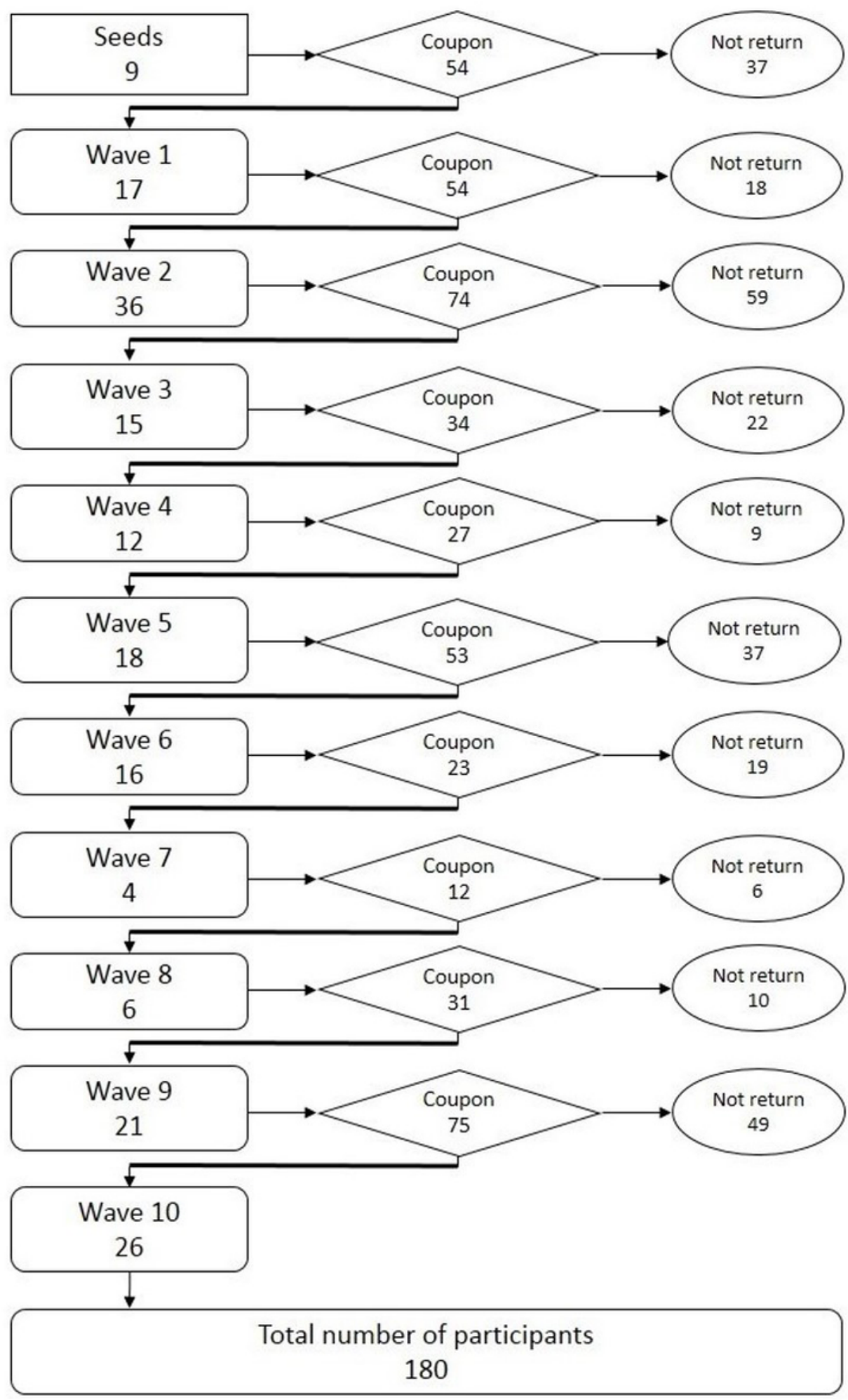

Figure 1

Flow chart of the number of participants recruited at each stage 


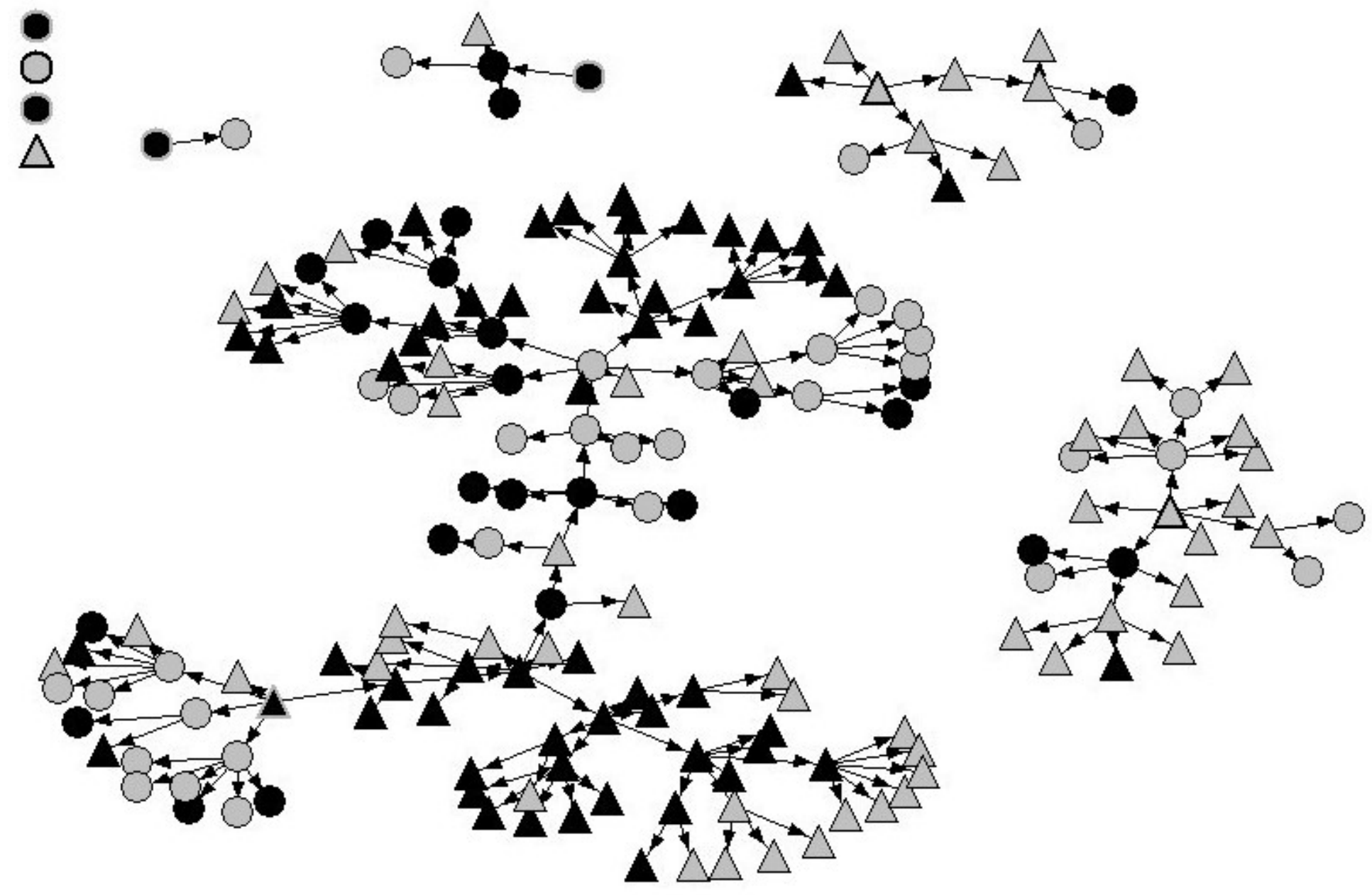

Figure 2

Visualization of the recruiting network of respondents from the 9 seeds. Legend of Figure 2: Circles indicate girls, triangles indicate boys, gray indicates never had sexual intercourse, black indicates had sexual intercourse. 